\title{
SUPERFÍCIE POTENCIOMÉTRICA E POSSÍVEIS FONTES DE CONTAMINAÇÃO DO AQUÍFERO PARECIS NO MUNICÍPIO DE VILHENA - RO, BR
}

\author{
Potentiometric surface and possible sources of contamination of the Parecis aquifer in the \\ municipality of Vilhena, $\mathrm{RO}, \mathrm{Br}$
Calina Grazielli Dias Barros¹, Ana Lucia Denardin da Rosa², José Luiz Silvério da Silva $^{3}$, Gislayne Alves Oliveira ${ }^{3}$, Luiza Girard Teixeira ${ }^{1}$, \\ Raphael Bruno da Silva Sampaio ${ }^{1}$ \\ ${ }_{1}^{1}$ Universidade Federal do Pará \\ ${ }^{2}$ Universidade Federal de Rondônia \\ ${ }^{3}$ Universidade Federal de Santa Maria
}

Resumo

\begin{abstract}
O controle e a preservação da qualidade das águas subterrâneas são as principais tarefas a serem realizadas quando se trata de planejamento ambiental desse recurso. Desta forma, o presente estudo tem como objetivo determinar as linhas de fluxo das águas subterrâneas no município de Vilhena-RO, Região Amazônica. Foram levantados dados de poços e mapeadas as fontes potenciais de contaminação incluindo-se os postos de combustíveis, cemitério municipal, poços de abastecimento contaminados e lixões desativados. Por meio do mapa de superfície potenciométrica foi possível constatar alguns pontos vulneráveis, como o poço número 27, de responsabilidade do Serviço Autônomo de Águas e Esgoto, o qual está localizado em uma área de convergência de fluxos, podendo assim receber cargas contaminantes oriundas do cemitério municipal e de dois lixões desativados. Sendo assim, o estudo da superfície potenciométrica do Aquífero Parecis é uma valiosa ferramenta de espacialização em Sistema de Informações Geográficas que permite, através da observação do mapa gerado, localizar os melhores pontos para instalação de novos poços de abastecimento, postos de combustíveis, entre outros, fornecendo subsídios para o processo de gestão, ocupação dos solos e controle da explotação das águas subterrâneas em escala municipal.
\end{abstract}

Palavras-chave: Superfície Potenciométrica. Água Subterrânea. Contaminação. Aquífero Parecis. Vilhena.

Abstract

The control and preservation of groundwater quality are the main tasks to be performed during environmental planning of this resource. Thus, the present study aims to determine the lines of groundwater flow in the municipality of Vilhena, Amazon Region. This town gets its water supply from the Parecis Aquifer. Potencial sources of contamination were identified including gas stations, municipal cemetery, contaminated supply wells and inactive dumps. Through the potentiometric surface map was determined a vulnerability of the well number 27 which is the responsibility of the Autonomous Service for Water and Sewage, which is located in an area of convergence of flows, and thus can receive contaminant loads coming from the municipal cemetery and two inactive dumps. Thus, the study of the potentiometric surface of the Parecis Aquifer is a valuable tool for spatialization of Geographical Information System that allows, by observing the generated map, locate the best spots for installation of new supply wells, gas stations, providing subsidies for management process, land use and control the exploitation of groundwater at the municipal level.

Keywords: Potentiometric surface, Groundwater, Contamination, Parecis Aquifer, Vilhena. 


\section{Introdução}

A água é a substância mais abundante da superfície terrestre, com aproximadamente 1,4 bilhões de $\mathrm{km}^{3}$ ocupando cerca de $71 \%$ da sua superfície (GRASSI, 2001). O Brasil é considerado um país privilegiado em termos de disponibilidade hídrica total, com aproximadamente $12 \%$ das reservas mundiais de água doce (ZUFFO et al., 2009) incluindo-se grandes reservas renováveis, nos vários sistemas aquíferos.

No país, a expansão territorial aconteceu levando em consideração as águas superficiais, principalmente na região Norte, Amazônica, na qual as margens dos rios eram ocupadas pelos ribeirinhos, onde as cidades foram sendo desenvolvidas (AZEVEDO, 2006). No entanto, tanto as águas superficiais como as subterrâneas, essas mais recentemente, vem sofrendo fortes pressões antrópicas como resultado da ampliação do número de captações por poços tubulares tanto em áreas urbanas quanto rurais. No município de Vilhena, no Estado de Rondônia, a única fonte de abastecimento humano, advém da água subterrânea do Aquífero Parecis. Não só em Vilhena, como em outras cidades brasileiras, não vem sendo tomados os devidos cuidados com esse recurso hídrico subterrâneo, o que contraria a lógica, pois o consumo desse recurso vem aumentando cada vez mais devido ao fácil acesso e baixo custo de perfuração e bombas submersas (IRITANI et al., 2011). Portanto, faz-se necessária a preservação desse bem, não somente porque representa uma das maiores porcentagens das águas doces de fácil acesso, mas também porque sua descontaminação é tecnicamente difícil e onerosa (ABERTI e SILVA, 2005).

A qualidade da água subterrânea pode ser comprometida por diversos fatores naturais e/ou de origem antropogênica, dentre eles o destino final dos resíduos industriais ou doméstico, os postos de combustíveis, o necrochorume advindo dos cemitérios e ainda a modernização da agricultura, que utiliza diferentes tipos de fertilizantes a base de Nitrogênio, Fósforo e Potássio/NPK bem como agroquímicos. Dessa forma, são necessários estudos da proteção da qualidade natural dos aquíferos e um controle das atividades antrópicas, através de poços de monitoramento, para evitar possíveis contaminações e fazer um planejamento dos usos para a atual e futuras gerações. Buscando-se então, uma maneira de planejar o ordenamento das ocupações populacionais através do uso do solo urbano e instalações de indústrias com alto potencial de contaminação, tornam-se necessários estudos de fluxo subterrâneo estimados através da superfície potenciométrica ${ }^{1}$ da área de estudo. Deve-se fazer a estimativa da direção de fluxo e um levantamento das atividades potencialmente poluidoras, como os postos de combustíveis, as oficinas mecânicas, os cemitérios, os lixões ativos ou abandonados, os lava rápidos, além do esgotamento sanitário in situ ${ }^{2}$ (TERRA et al., 2013).

Durante a prospecção, extração, armazenamento, transporte e utilização dos derivados do petróleo, vários acidentes de vazamento ocorrem com frequência o que pode causar sérios danos aos ecossistemas, aos solos, e as águas subterrâneas contidas em distintos aquíferos.

Salienta-se que os vazamentos de combustíveis são considerados graves problemas ambientais, devido às dificuldades no tratamento da água contaminada (YANXUN, 2011). De acordo com a Resolução $N^{\circ} 273$ (CONAMA, 2000), são exigências para o licenciamento ambiental de postos de combustíveis: a caracterização hidrogeológica com definição do sentido de fluxo das águas subterrâneas; a identificação das áreas de recarga; a localização de poços de captação destinados ao abastecimento público ou privado registrados.

Essa resolução considera que todo sistema de armazenamento de derivados de petróleo e outros combustíveis, são potenciais poluidores e geradores de acidentes ambientais, podendo contaminar tanto águas superficiais, quanto as subterrâneas contidas nos aquíferos. A gasolina, o diesel, assim

\footnotetext{
${ }^{1}$ A superfície potenciométrica é o lugar geométrico dos pontos que determinam a altura do nível d'água de um aquífero, determinado em relação ao Datum estabelecido, o que representa a direção do fluxo das águas subterrâneas (DINIZ e MICHALUATE, 2001).

${ }^{2}$ Refere-se à disposição de esgotos no solo através de fossas, valas e sumidouros, que geralmente estão próximos aos poços tubulares para captação de água subterrânea (FAZZIO, 2010).
} 
como o álcool produzem voláteis e tóxicos, gerando gerar subprodutos indesejáveis que alteram à água natural, dependo sempre de sua carga (VENÂNCIO, 2008).

Os cemitérios representam um grave problema nos centros urbanos ou de expansão urbana com sérias consequências ambientais em certos locais, em especial, para as águas subterrâneas. Através do processo de lixiviação a água proveniente de chuvas pode infiltrar em túmulos, levando para a zona não saturada o necrochorume (líquido que possui compostos orgânicos, odor desagradável, uma tonalidade castanho-acinzentada e ainda apresentar organismos patogênicos), atingindo, dessa forma, a zona saturada que pode contaminar o lençol freático (KEMERICH et al., 2010). As resoluções №335 (CONAMA, 2003); №368 (CONAMA, 2006) e №402 (CONAMA, 2008) tratam do licenciamento ambiental de cemitérios. Citam-se ainda estudos de Costa Silva e Malagutti Filho (2009) e Pacheco (1986) que enfatizam que para uma eficiente gestão ambiental dos cemitérios, deve-se evitar uma alteração na qualidade do aquífero freático. Cita-se a legislação do Estado do Rio Grande do Sul, onde a gestão ambiental municipal e o licenciamento das atividades de impacto local como os cemitérios, com área até dois hectares vem sendo realizado pelas Prefeituras Municipais, que contam com equipe técnica multidisciplinar (SEMA, 2014).

De acordo com Żychowski (2012), estudos de impacto dos corpos na água subterrânea foram efetuados em diferentes países, em diferentes períodos em diversas condições de meio ambiente, gerando-se uma gama de resultados. De um modo geral, foram confirmadas as altas concentrações de íons nas imediações das covas (50 centímetros até 1 metro abaixo do nível do sepultamento de corpos). As altas concentrações desses contaminantes rapidamente sofrem redução com o aumento da distância em relação aos corpos enterrados em função das características de porosidade/permeabilidade dos solos/rochas sedimentares clásticas (HEATH, 1982), bem como são uma função de suas proporções em fração finas, diâmetros das partículas argila $(<0,002 \mathrm{~mm})$, silte $(0,002-0,062 \mathrm{~mm})$ e areias $(0,062-0,062 \mathrm{~mm})$ Classificação de Wentworth (LEINZ e AMARAL, 1987).

Já os resíduos sólidos descartados de forma inadequada, como é caso de muitos "lixões" em várias cidades brasileiras, possuem uma carga contaminante que dependendo da sua origem, composição e do teor de umidade em que foram dispostos no ambiente, são considerados fontes potenciais de contaminação (FOSTER \& HIRATA, 1993 e FOSTER et al. 2006) .

Desta forma, o presente estudo teve como objetivo a determinação da tendência de direção da superfície potenciométrica no Aquífero Parecis, no Município de Vilhena (RO) correlacionando-se com as possíveis fontes de contaminação que possam comprometer a qualidade natural da água para os ecossistemas e para o consumo humano, ressaltando-se a utilidade desta metodologia para a gestão de recursos hídricos subterrâneos.

\section{2 ÁREA DE ESTUDO}

O estudo foi desenvolvido no Aquífero Parecis, localizado no município de Vilhena, sudoeste da Amazônia Legal Brasileira e na parte sul do Estado de Rondônia (Figura 1). Possui uma área de aproximadamente $11.518,941 \mathrm{~km}^{2}$ e uma população estimada de cerca de 76.202 habitantes (IBGE, 2010).

De acordo com a CPRM (2008), no Mapa de Domínios e Subdomínios, a Bacia do Parecis enquadrase nas Bacias Sedimentares, a qual apresenta alta a média favorabilidade hidrogeológica e correspondem as unidades geológicas Furnas, Aquidauana, Fazenda da Casa Branca, Rio Ávila, Salto das Nuvens e Utiariti. Litologicamente inclui uma predominância de arenitos de granulometria variável, muitas vezes bem selecionados e bimodais, além de conglomerados, argilitos e siltitos. Os aquíferos desta bacia possuem altas vazões, com produção entre 100 e $200 \mathrm{~m}^{3} / \mathrm{h}$, apresentando água de boa qualidade química. Bahia et al. (2006) citam que a Bacia dos Parecis está localizada na região centro-oeste do Brasil, na porção sudoeste do Cráton Amazônico, entre os cinturões de cisalhamento Rondônia e Guaporé. 


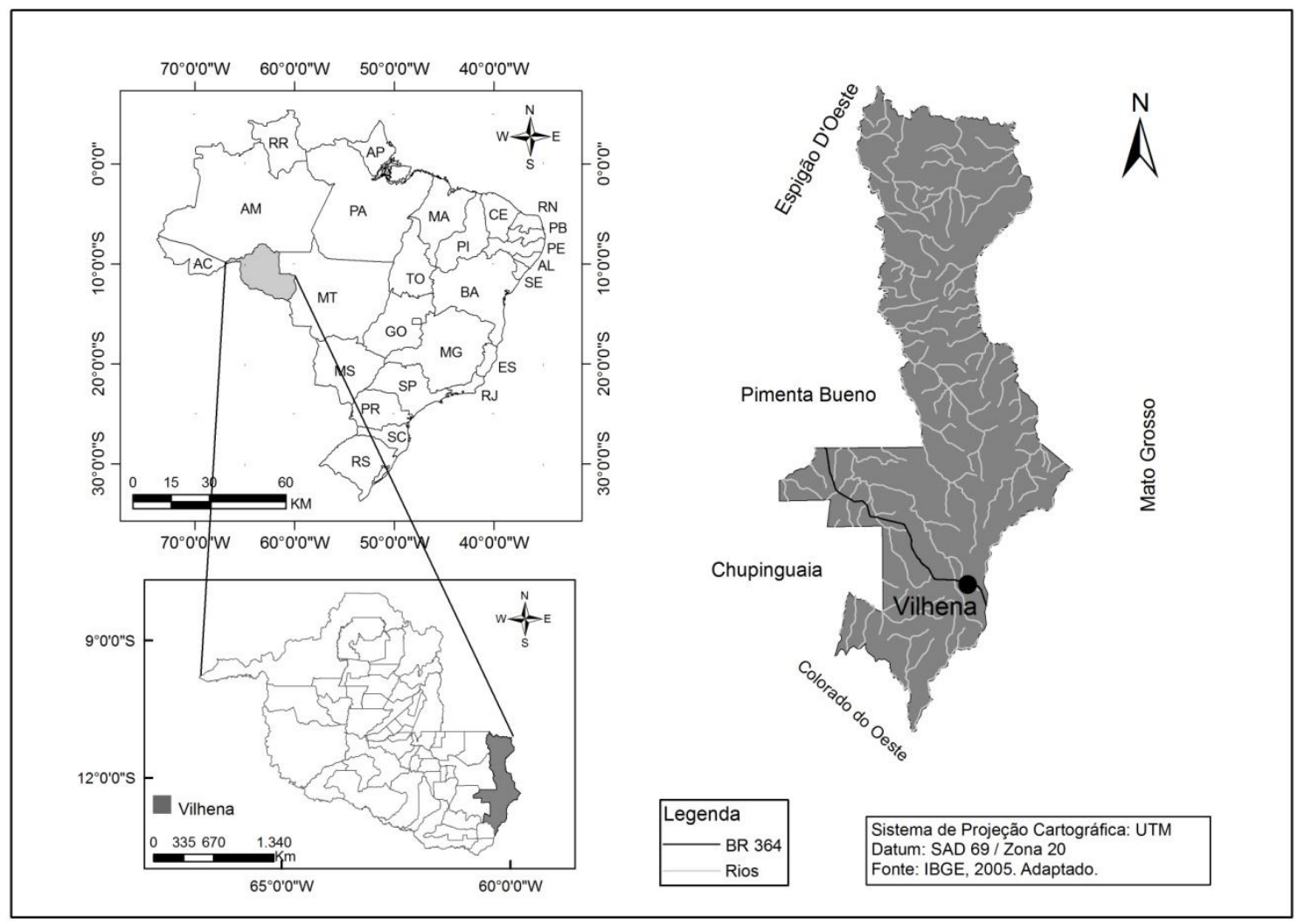

Figura 1 - Mapa de Localização do município de Vilhena - RO, BRASIL.

Fonte: IBGE, 2005 (Adaptado)

Já a ANA (2005) considera o Aquífero Parecis como do tipo poroso, livre com uma área de recarga estimada em $88.157 \mathrm{~km}^{2}$, pertencente à Região Hidrográfica Amazônica, apresentando uma espessura média de $150 \mathrm{~m}$, e ainda cita uma precipitação pluviométrica anual, da ordem de $1.890 \mathrm{~mm}$, apresentando uma reserva renovável de $2.324,0 \mathrm{~m}^{3} / \mathrm{s}$ e explotável da ordem de $464,8 \mathrm{~m} 3 / \mathrm{s}$.

O Município de Vilhena está localizado na parte leste do Aquífero Parecis, pertencendo a Bacia dos Parecis, na região limítrofe entre os estados do Mato Grosso e Rondônia (OLIVEIRA e BRITO, 1998). Bahia et al. (2006) descreveram a ocorrência de afloramentos da Formação Salto das Nuvens, constituída por conglomerados, depositados no Período Cretáceo, pertencente ao Grupo Parecis. Consideraram que o contato inferior do Grupo Parecis dá-se com arenitos eólicos da Formação Rio Ávila e, o contato superior, com uma cobertura Terciária.

Vilhena, quando comparada com as demais cidades do Estado de Rondônia, apresenta uma altitude média de $595 \mathrm{~m}$ que é considerada elevada, sendo esse diferencial característico de sua localização na Serra dos Parecis. A altitude média nos municípios desse estado é da ordem de $203 \mathrm{~m}$. Já o município de Candeias do Jamari apresenta a menor elevação superficial do terreno, com uma cota altimétrica de $87 \mathrm{~m}$, enquanto que o segundo município mais elevado, seguido de Vilhena é a cidade de Colorado do Oeste com cota altimétrica da ordem de $419 \mathrm{~m}$.

$\mathrm{Na}$ área urbana do município em estudo foram encontrados alguns pontos potenciais de contaminação das águas subterrâneas como é caso do cemitério municipal, o qual apresenta uma área de aproximadamente 734 ha. Apresenta ainda três lixões desativados, sendo que o terceiro ficou inoperante no ano de 2013. Em julho de 2013 foi inaugurado no município um Aterro Sanitário, para onde são destinadas aproximadamente 60 toneladas diárias de resíduos sólidos, podendo alcançar até 130 ton/dia, com possibilidade de atender os municípios do Cone Sul do estado (MARILZA, 2014). 


\section{MATERIAL E MÉTODOS}

Os procedimentos realizados para obtenção, tratamento dos dados para a efetivação do objetivo proposto são apresentados no fluxograma da Figura 2.

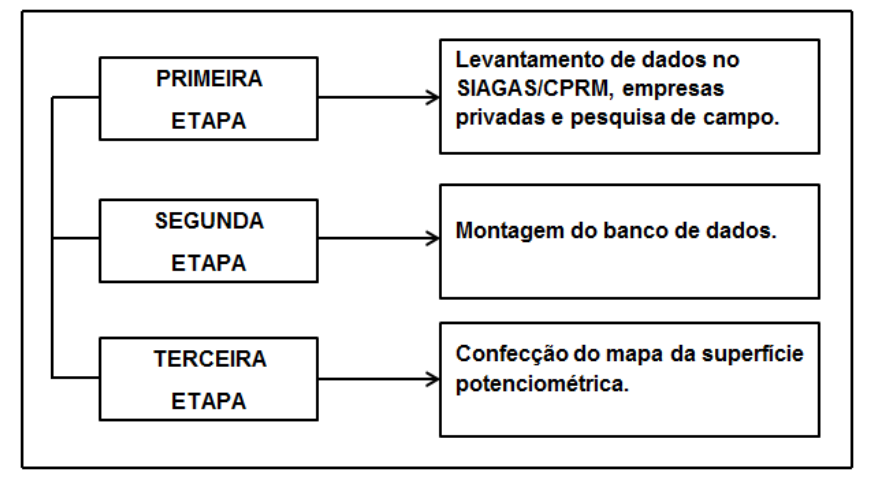

Figura 2 - Fluxograma das etapas realizadas no estudo.

Na primeira etapa do trabalho, foi realizada uma pesquisa no Sistema de Informações de Águas Subterrâneas (SIAGAS/RIMAS/CPRM) e na empresa privada, responsável pelas perfurações de poços no Município de Vilhena. Segundo o SIAGAS, no município existem 167 poços cadastrados, entretanto, somente 32 foram utilizados, pois apresentaram informações completas das captações por poços, tais como: as coordenadas no sistema geográfico e Universal Transversa de Mercator/UTM; os estratos litológicos; o nível estático (N.E. em metros); bem como foi obtida a autorização dos proprietários das captações para realização dessa pesquisa. Foram obtidas as mesmas informações em mais 4 poços tubulares da empresa de perfuração, totalizando-se assim, 36 poços para a determinação da tendência da superfície potenciométrica na estimativa da direção do fluxo subterrâneo.

Heath (1982) considera a superfície potenciométrica, uma superfície que representa a carga total em um aquífero. Ou seja, ela representa a altura acima do Datum de referência, a qual o nível da água se eleva num poço bem vedado, que penetra o aquífero. Portanto, considerou-se a relação entre a cota altimétrica registrada na superfície do poço em relação ao nível de água registrado na sua perfuração.

Foram coletados dados em campo, através de visitas aos proprietários dos poços, sendo obtidas as cotas altimétricas, através do uso do GPS Garmin Etrex Vista H 2.8. Também foram utilizadas as imagens do Google Earth disponíveis na Web, na espacialização das coordenadas geográficas, das cotas altimétricas do terreno relativas aos pontos potenciais de contaminação, a saber: antigos lixões desativados do município, o cemitério municipal e os postos de combustíveis localizados no meio urbano. As leituras das informações do GPS foram coletadas no sistema de coordenadas UTM, adotando-se o fuso $20 \mathrm{~S}$, e o Datum horizontal SAD69. Todas esses dados foram tabelados em planilhas eletrônicas Microsoft Excel, sistematizados, e então usados nas avaliações espaciais em SIG.

$\mathrm{Na}$ segunda etapa realizou-se a montagem do banco de dados no programa computacional Microsoft Excel, referente aos dados coletados dos poços cadastrados no SIAGAS, da empresa perfuradora e dos dados de campo. Esse banco de dados foi utilizado para a interpolação no Programa Surfer 8 e utilizou-se a metodologia de interpolação matemática denominada krigagem. Esse método geoestatístico é mais recomendado e foi considerado o melhor na minimização dos erros de inferências de informações (KITANIDIS, 1997). “Krigagem é um processo de estimação por médias móveis, de valores de variáveis distribuídas no espaço a partir de valores adjacentes, enquanto considerados como interdependentes por uma função denominada semivariograma" (LANDIM et al., 2002).

De acordo com Dalto (2002): “Um semivariograma pode ser definido como a metade da variância das diferenças entre valores da variável de interesse em pontos separados por uma 
distância, considerando a média quadrática das diferenças entre os valores nos pontos, distribuídos no espaço."

Na terceira etapa, já com os dados organizados e espacializados no programa Surfer 8 obteve-se os mapas temáticos com os isovalores da superfície pontenciométrica e tendência de direção de fluxo das águas subterrâneas. Para gerar esses mapas foram usados o nível estático extraído do SIAGAS/CPRM e as cotas altimétricas dos poços, adquiridas em campo com uso do GPS.

\section{RESULTADOS E DISCUSSÃO}

Com a identificação dos poços tubulares utilizados no estudo foi possível observar que os mesmos estão distribuídos em sua grande maioria na área urbana do Município de Vilhena (Figura 3).

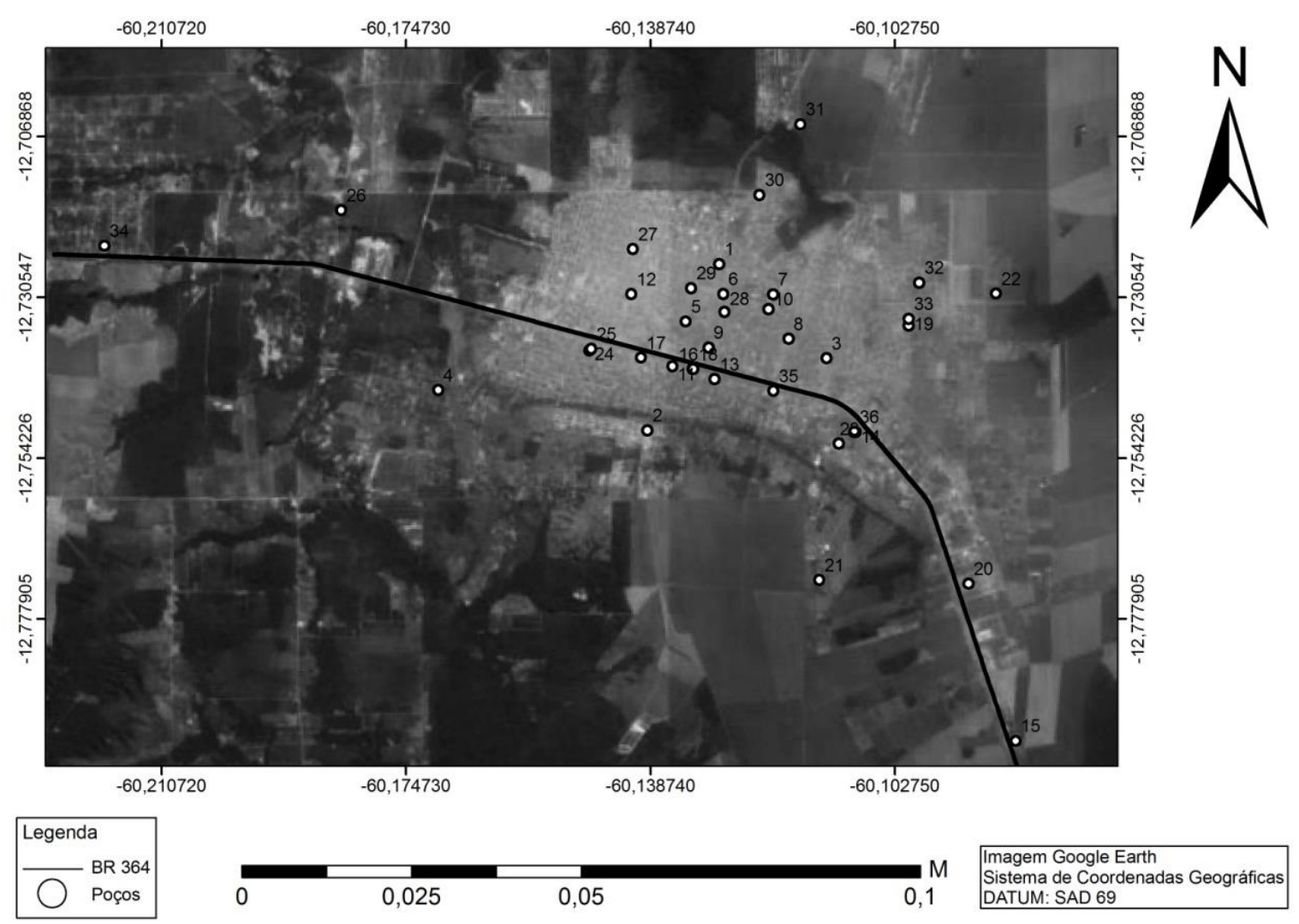

Figura 3 - Mapa de localização dos poços em Vilhena-RO/BRASIL

Salienta-se que no município o abastecimento doméstico, industrial e o desenvolvimento de atividades agrícolas acontecem com uso das águas subterrâneas. Constatou-se nas visitas de campo que algumas indústrias, residências e áreas agrícolas possuem seus próprios poços tubulares e respectivos reservatórios em caixas d'águas, não utilizando a água fornecida pelo pela empresa de abastecimento - SAAE. Isso pode ser explicado em parte, devido aos problemas enfrentados de intermitência no abastecimento público bem como redução no custo de tarifas com a utilização de águas subterrâneas captadas do Aquífero Parecis.

De acordo com os dados litológicos analisados no estudo, os poços, em relação ao grau de confinamento do aquífero, foram considerados como pertencentes ao aquífero confinado, uma vez que apresentaram uma expressiva quantidade de fração argila, impermeável, em sua composição, o que acaba por dificultar a penetração e o movimento dos contaminantes potenciais. Os poços do estudo espacializados nas Figuras 3 e 4, que se enquadram na condição de confinados são: 
a) 8 poços pertencentes ao $\operatorname{SAAE}(1,2,14,19,24,25,33$ e 36$)$;

b) 4 poços particulares $(4,11,13$, e 35$)$;

c) 1 poço de abastecimento escolar (8);

d) 1 poço de monitoramento do RIMAS/CPRM (18);

e) 2 poços para abastecimento residencial (30 e 32);

f) 1 poço da associação rural (34).

Já os poços que se enquadraram no aquífero não-confinado (livre), apresentaram em sua composição uma grande quantidade da fração areia, que por apresentar maior porosidade (relação entre o teor de vazio e o volume total da rocha) e por ser mais permeável ao fluxo de contaminantes, apresentaria uma maior facilidade de contaminação. Os poços encontrados nesse tipo de condição de aquífero livre são:

a) 7 poços de abastecimento do $\operatorname{SAAE}(5,7,12,21,27,28$ e 29);

b) 6 poços particulares $(6,10,15,16,17$ e 20$)$;

c) 2 poços em igrejas ( 3 e 9 );

d) 3 poços de monitoramento do RIMAS/CPRM (22, 23 e 31);

e) 1 poço da CPRM (26).

Os poços de números: 5, 7, 12, 21, 27, 28, 29 e 26 são utilizados para abastecimento público, e se encontram suscetíveis a contaminação por estarem no aquífero livre. Salienta-se que um poço uma vez contaminado a sua descontaminação é difícil e onerosa.

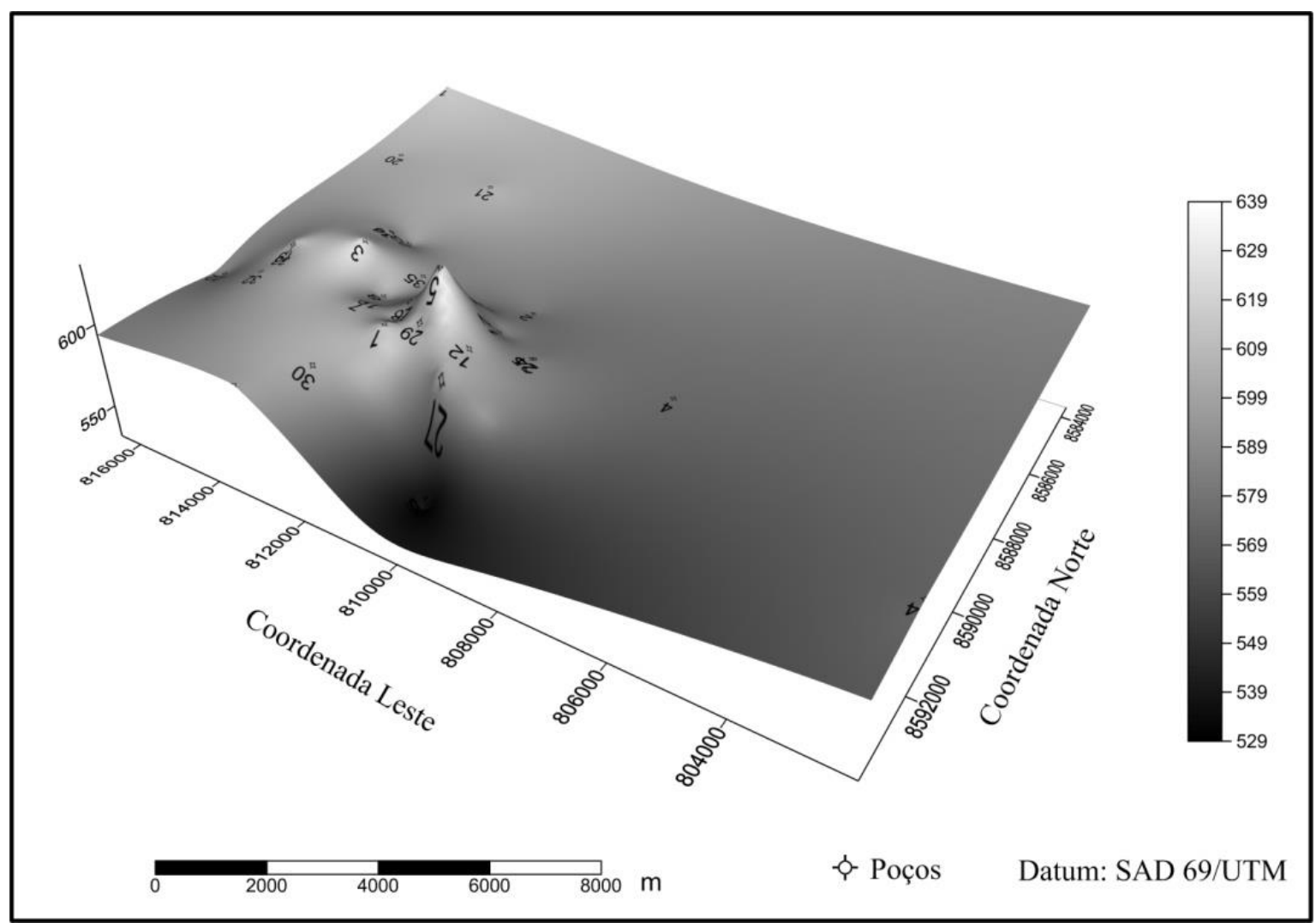

Figura 4 - Mapa das cotas altimétrica (m) na boca dos poços da área de estudo, Sistema UTM* (O mapa foi rotacionado no sentido horário para melhor visualização).

A análise da Figura 4, que representa a superfície topográfica é muito importante, pois suas informações têm grande valor na interpretação do sentido e movimento da água subterrânea. É possível observar na Figura 4 que o poço № 26 está localizado na região de menor atitude da área de estudo (529 m), ocupando um baixo valor potenciométrico em cores negras na porção Norte do cartograma. Já o poço no 5 , localizado na cota altimétrica mais elevada, de 639m, ocupa um alto valor potenciométrico (cores claras Figura 5), ou seja, um divisor de águas subterrâneas juntamente com os poços №3, 19 e 33. A altitude média estimada foi de $601 \mathrm{~m}$. 
Essa variação topográfica encontrada na área de estudo pode explicar as convergências e divergências nas direções de fluxos apresentadas no mapa da superfície potenciométrica obtido (Figura 5 e 6), onde é possível visualizar uma mudança na direção do fluxo na região com maior superfície potenciométrica (poço № 5) para regiões com menor superfície potenciométrica (poço № 26) indicando nesse setor do cartograma uma direção preferencial de Sudeste para Noroeste.

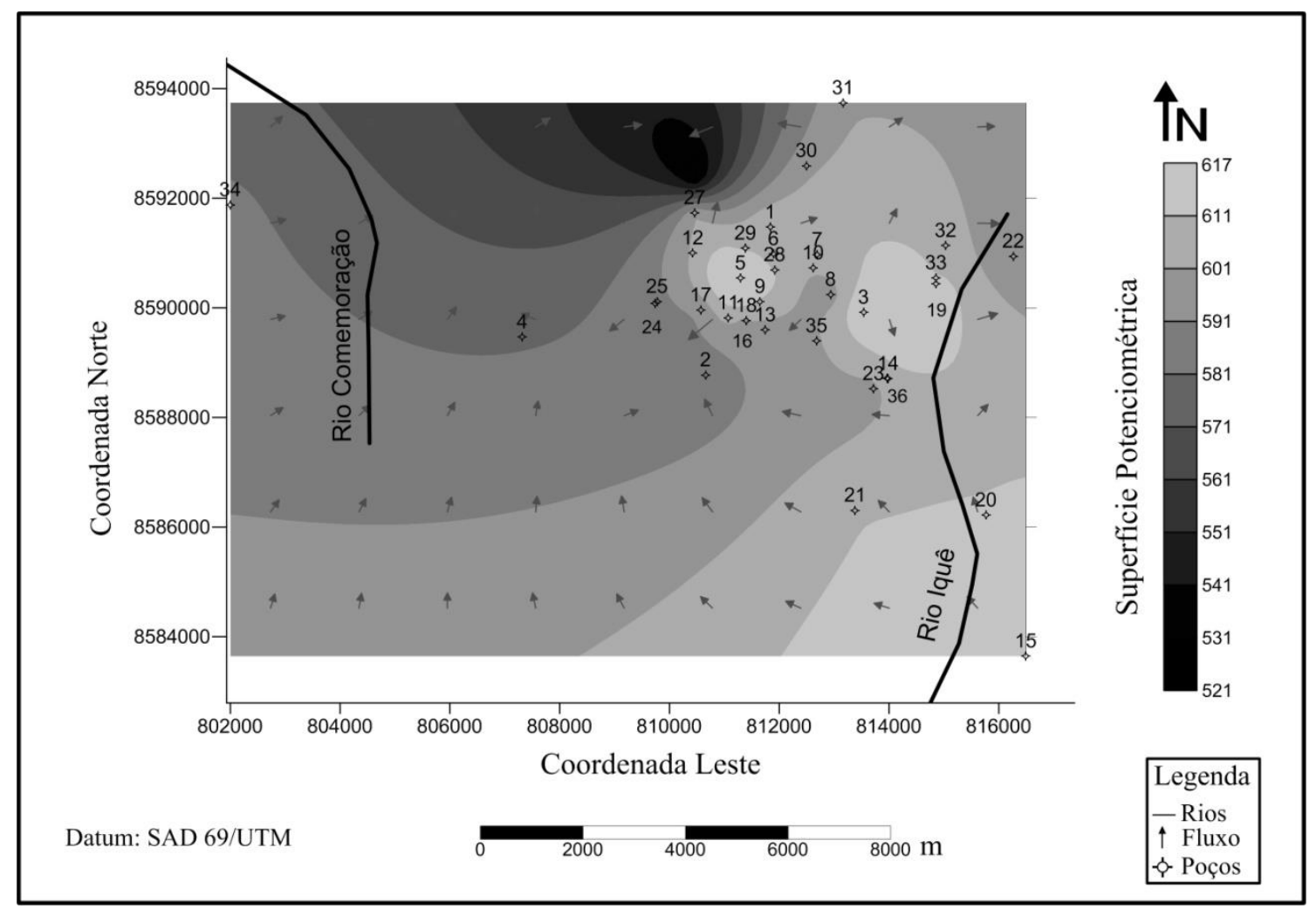

Figura 5 - Direção do fluxo subterrâneo no Aquífero Parecis no município de Vilhena-RO/BR, Sistema UTM.

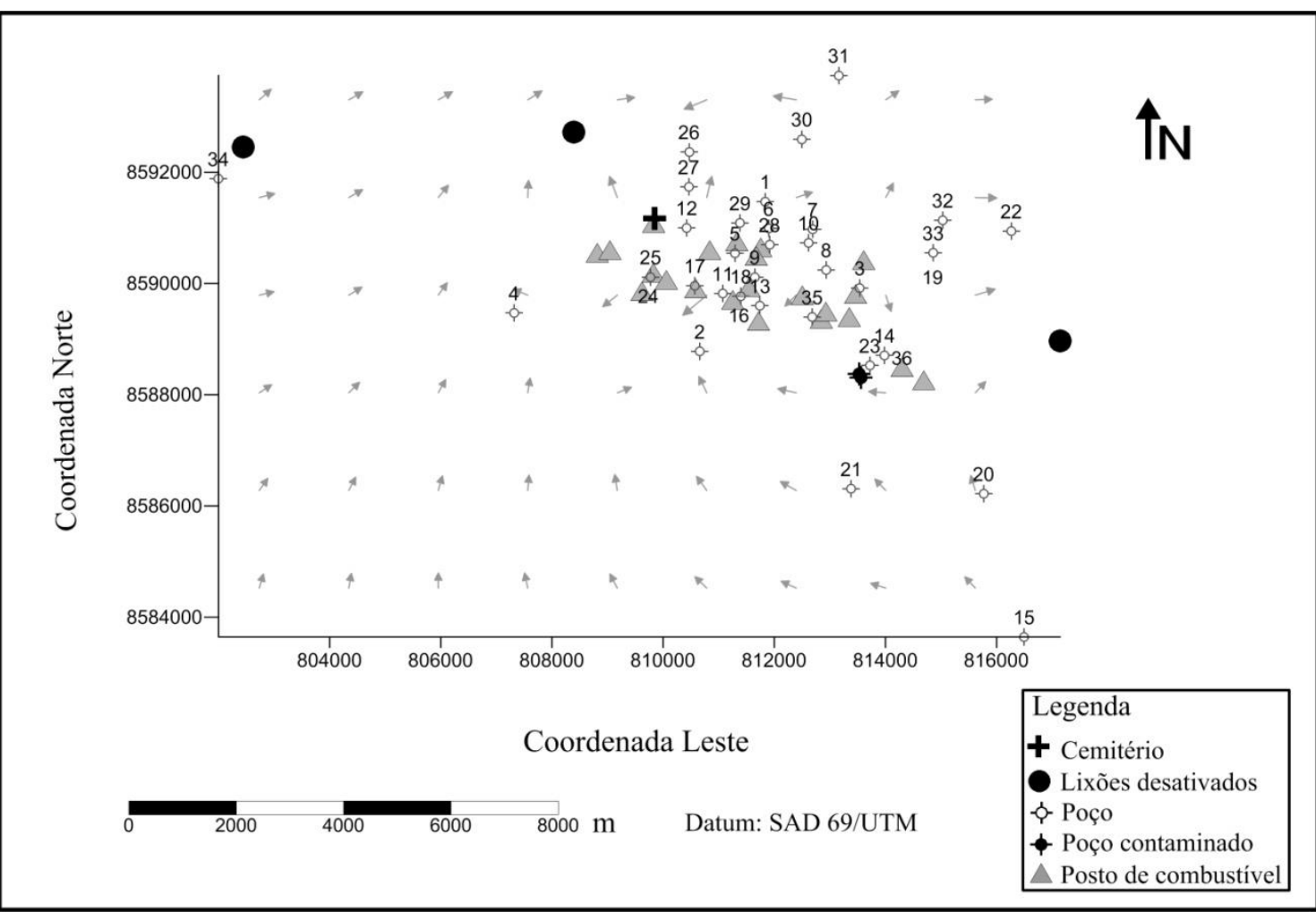

Figura 5 - Mapa de direção do fluxo com os pontos potenciais de contaminações. 
Analisando o mapa de tendência de direção de fluxo subterrâneo apresentado na Figura 5, observa-se também que os vetores (vetores no cartograma) indicam a direção da água subterrânea para o Rio Comemoração. A partir dessa espacialização estimou-se ocorrer uma contribuição do Aquífero Parecis para o Rio Comemoração, participando da sua perenização, em períodos de estiagem função mantenedora (ABAS/Wrege, 1997) na manutenção do fluxo de base dos rios. Assim, as captações de água subterrâneas localizadas próximas às calhas dos rios têm menos chances de ficar sem água corrente, em períodos menos chuvosos ou durante estiagens, devido à resposta aquífera ser suficiente para sua manutenção.

A partir das visitas de campo foram caracterizados 28 pontos potenciais de contaminação, localizados na área urbana de Vilhena, sendo eles caracterizados como: 22 postos de combustíveis, 1 cemitério municipal, 3 lixões e 2 poços tubulares, anteriormente utilizados para abastecimento doméstico, que estão desativados e lacrados uma vez que apresentaram contaminação das águas em tempos passados. A espacialização desses pontos potenciais de contaminação é apresentada no mapa da Figura 6 onde foram incluídos os vetores de fluxos subterrâneos em setores do cartograma contendo informações de poços ou estimados através do uso do interpolador krigagem no programa Surfer 8.

Assim, na espacialização no mapa da Figura 6, dos pontos potenciais de contaminação, plotadas juntamente com a direção do fluxo da água subterrânea servem como base para identificar as áreas de maior susceptibilidade à contaminação. Esses locais seriam aqueles sugeridos para monitoramento da qualidade da água subterrânea e instalação de poços de monitoramento.

Verifica-se que existem postos de combustíveis que se encontram em áreas com seu fluxo direcionado para áreas de baixo valor potenciométrico. Dessa forma é necessário ter atenção, não somente nas áreas dos pontos potenciais de contaminação, mas também naquelas onde estão direcionados os fluxos, em caso de ocorrência ou formação de plumas irão concentrar-se.

Atenção maior deve receber por parte dos gestores ambientais o poço de $\mathrm{N}^{\circ} 27$, o qual pertence à rede de abastecimento público (SAAE), tendo em vista que a direção do fluxo subterrâneo converge para sua localização e área de captação. Acrescentando-se a isso sua condição de aquífero nãoconfinado (livre), a qualidade da água oferecida por este poço pode estar comprometida ou ser comprometida futuramente, pois quando analisados em relação às possíveis fontes de contaminação, o mesmo está localizado em uma área que pode estar recebendo uma carga contaminante proveniente da provável pluma de contaminação oriunda do cemitério (necro-chorume) dos dois "lixões" desativados e, ainda, de alguns postos de combustíveis operando nesse setor.

\section{Conclusões}

O município de Vilhena tem o seu abastecimento público de água totalmente realizado de explotação do Aquífero Parecis, que conta com uma reserva renovável de água. Portanto, conhecer suas linhas de fluxo torna-se importante para o estabelecimento de uma rede de monitoramento da qualidade das águas subterrâneas buscando a proteção de sua qualidade natural.

A elaboração do mapa de direção do fluxo das águas subterrâneas em Vilhena torna-se uma importante ferramenta que permitirá o controle e preservação por meio de gestão dos recursos hídricos, pois pode ser um dos parâmetros base para o direcionamento de instalações de empreendimento consideradas possíveis fontes de contaminação (cemitérios, postos de combustíveis, oficinas mecânicas industriais e outros). Assim, esses mapas servem no planejamento ambiental e na ocupação dos solos, e principalmente, no auxílio à concessão de outorgas de direito de uso da água subterrâneas, evitando-se um colapso desse manancial renovável e buscando-se a saúde da população que consome essas águas subterrâneas. 


\section{Referências}

Aberti, E. A.; Silva, J. L.S. Estudo da vulnerabilidade natural dos aqüíferos no perímetro urbano de Tupanciretã/RS. In: Anais do1ํㅗㅇ Simpósio de Recursos Hídricos do Sul e 1o Simpósio de Águas da AUGM, 2005. Santa Maria, Brasil

Azevedo, R. P. (2006). Uso de água subterrânea em sistema de abastecimento público de comunidades na várzea da Amazônia central. Revista Acta Amazônica, 36 (3), 313- 320.

Bahia, R. B. C.; Martins-Neto, M. A.; Barbosa, M. S. C.; Pedreira, A. J. (2006). Revisão Estratigráfica da Bacia dos Parecis - Amazônia. Revista Brasileira de Geociências, 36 (4), 692-703.

BRASIL, Agência Nacional DE Águas - ANA. (2005). Disponibilidade e demandas de recursos hídricos no Brasil Cadernos de Recursos Hídricos. Avaiable from: $<$ http://arquivos.ana.gov.br/planejamento/planos/pnrh/VF\%20DisponibilidadeDemanda.pdf $>$. Acesso em: 01 set. 2014.

Companhia de Pesquisa e Recursos Minerais - CPRM. (2007). Mapa de Domínios e Subdomínios Hidrogeológicos do Brasil. Escala 1:2.500.000. CPRM, 1 CD - ROM.

Conselho Nacional de Meio Ambiente - CONAMA. Resolução no 273 de 29 de novembro de 2000. Estabelece diretrizes para o licenciamento ambiental de postos de combustíveis e serviços e dispõe sobre a prevenção e controle da poluição. Diário Oficial da União (Brasília). 2001 Jan 05.

Conselho Nacional de Meio Ambiente - CONAMA. Resolução no 335 de 03 de abril de 2003. Dispõe sobre o licenciamento ambiental de cemitérios. Diário Oficial da União (Brasília). 2003 maio 28.

Conselho Nacional de Meio Ambiente - CONAMA. Resolução no 368, de 28 de março de 2006. Altera dispositivos da Resolução no 335, de 3 de abril de 2003, que dispõe sobre o licenciamento ambiental de cemitérios. Diário Oficial da União (Brasília). 2006 mar 29.

Conselho Nacional de Meio Ambiente - CONAMA. Resolução no 402, de 17 de novembro de 2008. Altera os artigos 11 e 12 da Resolução no 335, de 3 de abril de 2003. Diário Oficial da União (Brasília). 2008 nov 18.

Costa Silva, R. W.; Malagutti Filho, W. (2009). Cemitérios: fontes potenciais de contaminação. Ciência Hoje, 44 (263), 24-29.

Dalto, L. A.; Oliveira, J. N. de; Lollo, J. A. (2002). Avaliação Do Potencial Hídrico do Aqǘf́fero Bauru em Votuporanga - SP. Ilha Solteira, SP.

Diniz, H. N.; Michaluate, W. J. (2001). Interpretação de testes de vazão em poços tubulares profundos, dimensionamento e especificações de bombas submersas. São Paulo, curso, impresso. 91 p.

Fundação Estadual de Proteção Ambiental - FEPAM. (2014). Licenciamento Ambiental. Rio Grande do Sul. Disponível em: <http://www.fepam.rs.gov.br/central/licenc_munic.asp>. Acesso em: 01 set. 2014.

Foster, S; Hirata, R. (1993). Determinação do risco de contaminação das águas subterrâneas: um método baseado em dados existentes. São Paulo: Instituto Geológico.(Boletim № 10).

Foster, S.; Hirata, R. A.C.; Gomes, D.; D'élia, M.; Paris, M. (2006). Proteção da qualidade da águas subterrânea. Um guia para usuários de água, prefeituras municipais e agentes ambientais. Banco Mundial.

Grassi, M. T. (2001). As Águas do Planeta Terra. Cadernos Temáticos de Química Nova na Escola Águas no planeta Terra, edição especial.

Heath, R. C. (1982). Hidrologia Básica de Água Subterrânea. Título original: Geological Survey Water Supply Paper. Trad. WREGE, M. \& POTTER, P. Associação Brasileira de Águas Subterrâneas Núcleo Sul-ABAS. 
Instituto Brasileiro de Geografia e Estatística - IBGE [Internet]. Cadastro de Localidades, 2010. Acesso em 04 mar. 2014. Disponível em: http://www.ibge.gov.br/home/geociencias/cartografia/territ_localidades.shtm >.

Iritani, M. A.; Ferreira, L. M. R.; Fernandes, A. J.; Ezaki, S(orgs). (2011). Projeto ambiental estratégico aqüíferos: síntese das atividades período 2007 - 2010 São Paulo: Instituto Geológico.

Kemerich, P. D. da C.; Descovi Filho, L. L. V.; Ucker, F. E.; Correio, C.V. F. (2010). Influência dos Cemitérios na Contaminação da Água Subterrânea em Santa Maria - RS. Revista Águas Subterrâneas, 24 (1), 129-141.

Kitanidis, P.K. (1997). Introduction to Geostatistics: Applications to Hydrogeology. Cambridge Univ, New York.

Lamdim, B.M.; Monteiro, C.R.; Corsi, A. C. (2002) Introdução à confecção de mapas pelo software Surfer. UNESP. Campus Rio Claro,ICGC, Texto Didático 08. Acesso em: 10 ago. 2014. Disponível em: <http://www.cprm.gov.br/publique/cgi/cgilua.exe/sys/start.htm?sid=35\&infoid=1463>.

Leinz, V.; Amaral, S. E. (1987). Geologia Geral. Editora Nacional. 8a edição.

Marilza. Sedam licencia aterro sanitário de Vilhena [Internet]. 23 de julho de 2013. Acesso em:18 fev. 2015. Disponível em: <http://www.sedam.ro.gov.br/index.php/ultimas-noticias/288-sedam-licenciaaterro-sanitario-de-vilhena>.

Oliveira, A.M. dos S.; Brito, S. N. A. de. (1998). Geologia de Engenharia. Associação Brasileira de Geologia de Engenharia, São Paulo.

Pacheco, A. (1986). Os cemitérios como risco potencial para as águas de abastecimento. Revista do Sistema de Planejamento e da Administração Metropolitana, 17, 25-37.

Terra, L. G., Löbler, C. A., Silva, J. L. S. (2013). Estimativa da Vulnerabilidade à Contaminação dos Recursos Hídricos Subterrâneos do Município de Santiago-RS. Rev. Elet. em Gestão, Educação e Tecnologia Ambiental, 10(10), 2208-2218.

Venâncio, L.T; Vidal, C.M de S; Moisa, R.E. (2008). Avaliação da percepção da importância da gestão ambiental em postos de combustíveis localizados na cidade de Irati, PA. Rev. Ambiência, 4(3), 397417.

Yanxun, S; Yani, W; Hui, Q; Yuan, F. (2011). Analysis of the Groundwater and Soil Pollution by Oil Leakage. Journal of SciVerse ScienceDirect, 11 (Part.B), 939-944.

Wrege, M. (1997). Termos Hidrogeológicos Básicos. Caderno Técnico no 4 da Associação Brasileira de Águas Subterrâneas. São Paulo, 32 p.

Zuffo, C. E.; Abreu, F. A. M. ; Cavalcante, I. N.; Nascimento G. F. (2009). Águas Subterrâneas em Rondônia: Análise Estatística de Dados Hidroquímicos, Organolépticos e Bacteriológicos. Revista do Instituto Geológico, 30 (1/2), 45-59.

Żychowski, J. (2012). Impact of cemeteries on groundwater chemistry: A review. Journal of Catena, 93, 29-37. 